(Não-)Lugares

A 


\title{
A VERTIGEM DO ARBITRÁRIO
}

Ivan Marques

Jornalista, Doutor em Literatura Brasileira (USP)

\begin{abstract}
RESUMO
Ricardo Domeneck, jovem poeta brasileiro que vive em Berlim, publicou dois livros de poemas e ensaios sobre poesia contemporânea que nos estimulam a reflexão sobre questões importantes da pós-modernidade, como o nomadismo, a flutuação entre territórios e a procura da identidade. Vivendo em "lugar nenhum", ainda assim o poeta acredita na influência do contexto ou dos condicionamentos culturais sobre a criação das obras de arte. Esse apego ao contexto se traduz, na verdade, em fascínio pelo acaso (contra o "logocentrismo" moderno) e em supervalorização da subjetividade (apesar do "descentramento" pós-moderno).
\end{abstract}

\section{PALAVRAS - CHAVE}

Ricardo Domeneck. Poesia brasileira contemporânea.

Cultura pós-moderna.

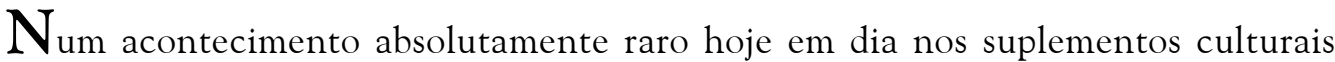
da grande imprensa, o caderno Ilustrada, da Folha de S.Paulo, dedicou recentemente uma de suas capas ao lançamento conjunto dos livros de três jovens poetas, com idade em torno dos trinta anos e integrantes, portanto, da "novíssima" geração da poesia brasileira. Angélica Freitas, Marília Garcia e Ricardo Domeneck são os autores, respectivamente, de Rilke shake, 20 poemas para o seu walkman e a cadela sem Logos. Dando ênfase aos traços definidores de um elo geracional, a reportagem da Folha - a primeira de uma série de resenhas publicadas em jornais e revistas - os qualifica desde o princípio como nômades. ${ }^{1} \mathrm{O}$ título "Perdidos no espaço" indica uma condição comum aos três poetas, a errância espaço-temporal - o tráfego entre vários países despertando dilemas de identidade e o acúmulo cada vez maior de referências. Ao mesmo tempo, também alude com ironia ao caráter deslocado e anacrônico do poeta no mundo de hoje, essa figura tão associada ao passado, que já não goza de nenhum prestígio cultural, não encontrando lugar no ranking de celebridades do século XXI. Sendo assim, por que os poetas em questão causaram tanta curiosidade? Qual o interesse dessa "poesia em trânsito"² no nosso panorama literário e cultural?

${ }^{1}$ Cf. TERRON. Perdidos no espaço. Os livros dos três poetas foram publicados na coleção "Ás de colete", das editoras 7Letras e Cosac Naify.

${ }^{2}$ Esse é o título de um artigo escrito pelo poeta Fernando Paixão (cf. Cult, n. 112). 
No poema "Sempre o exílio", publicado no seu livro de estréia, Carta aos anfíbios, de 2005, Ricardo Domeneck trata diretamente dos temas da errância e da identidade.

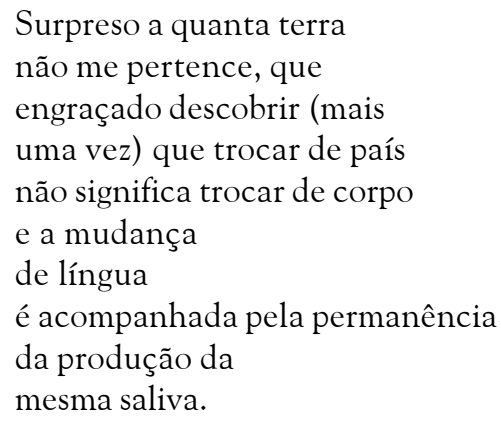

A experiência do exílio, que à época da ditadura tinha caráter político, na história brasileira recente se tornou uma espécie de solução compensatória, na esfera privada, para o sentimento de perda de auto-estima (ou identidade) e a falta de perspectiva, entre outros desencantos com o país. Um filme emblemático da década de 1990, Terra estrangeira, dirigido por Walter Salles e Daniela Thomas, retrata justamente a vergonha da condição de ser brasileiro. No caso da produção cinematográfica, a euforia provocada pela reforma neoliberal do governo Fernando Henrique Cardoso propiciaria, logo em seguida, um interesse renovado pelas paisagens e peculiaridades locais (o sertão, a favela etc.), embora distinto do gesto utópico que havia animado os diretores do Cinema Novo, em virtude da constatação realista dos vícios que permanecem desde as origens do país. ${ }^{3}$ A literatura, entretanto, parece não ter encontrado estímulos nesse quadro de estabilidade econômica e otimismo. E as questões nacionais, que hoje também soam como anacrônicas, pulverizadas no contexto da cultura globalizada, vêm perdendo espaço cada vez mais para temas típicos da pós-modernidade, como o individualismo, a desterritorialização, o cosmopolitismo, o consumismo e a cultura de massa.

Nascido em Bebedouro (SP), em 1977, Ricardo Domeneck vive há sete anos em Berlim, onde dá aulas de inglês, comanda festas como DJ e organiza performances multimídia, entre outras atividades. Ele conta que descobriu a poesia na adolescência, quando estudava nos Estados Unidos, aprendendo a ler Poe, Walt Whitman, Emily Dickinson e Salinger. Entre seus poetas favoritos, costuma citar language poets, autores da França, dos Estados Unidos, da Argentina, de Portugal. Também menciona com freqüência Murilo Mendes, Hilda Hilst, Orides Fontela e Paulo Leminski. Mas deixa claro, em seus textos e entrevistas, o distanciamento em relação à nossa reverenciada tradição poética e seu desdém pelas "intrigas de boteco" da poesia brasileira. Com efeito, é difícil filiar seu trabalho poético às grifes de que dispomos: modernismo, cabralismo, concretismo, o lirismo marginal da década de 1970 ou a poesia pós-utópica e "refinada" dos anos 1980 e 90 . Trata-se realmente de um poeta desterrado, rompido com a tradição nacional, embebido de poesia estrangeira, da filosofia de Wittgenstein, das performances de John Cage, da arte de Lygia Clark e Nan Goldin, da música de Björk e Yoko Ono, do cinema de Kieslowski e Lars Von Trier. Ultimamente, vem realizando experimentos com

${ }^{3}$ Cf. NAGIB. A utopia no cinema brasileiro. 
a mistura de poesia, vídeo e performance. Passeia entre as artes com a mesma desenvoltura com que, na sua poesia, cruza diversas vezes o oceano - embora advirta que "trocar de país" não significa "trocar de corpo". No contexto do exílio, a identidade original não apenas se mantém como se aclara e reforça. Tudo que a "pele estrangeira" produz é o desconforto de um corpo ilegal e inseguro - uma condição de invisibilidade particularmente penosa para temperamentos inquietos como o de Ricardo Domeneck, ansiosos por praticar uma arte de intervenção.

Se o exílio é eterno e inescapável, como enfatiza o título do poema, viajar não significa apenas vagar sem direção por todos os territórios, num presente desprovido de futuro, a exemplo dos nômades do transvanguardismo pós-moderno. ${ }^{4}$ A experiência de aprender línguas e conhecer novos contextos, por mais divertida e estimulante que seja, não elimina a consciência do corpo, o clamor das origens, o condicionamento do nome e do sobrenome. A contingência tem importância, mas o que se destaca é o indivíduo que a sofre, valoriza e, em última instância, escolhe. Na poesia de Domeneck, o eu, embora flutuante e descentrado, ocupa lugar central.

\section{Sempre digo ao \\ telefone meu \\ nome querendo \\ dizer sou eu}

Esses são os versos de abertura do poema-livro "Dedicatória dos joelhos", a primeira das três seções de a cadela sem Logos. No dizer do autor, trata-se de um "poema-emsérie que medita e performa as relações identidade/realidade/acaso/atenção/contexto", cujos fragmentos começaram a ser escritos depois da leitura de uma carta de Emily Dickinson, cheia de pormenores cotidianos, encerrada com a expressão forgive me the personality. ${ }^{5} \mathrm{~A}$ reflexão sobre o contexto e a identidade pessoal ocupam boa parte de seus artigos e poemas, que ele prefere chamar de textos. Para Domeneck, "todo poeta carrega em si os condicionamentos de sua estrutura individual, movendo-se num contexto coletivo". ${ }^{6}$ Ninguém escapa, segundo ele, aos condicionamentos culturais, econômicos e sociais que produzem, no momento preciso, a soberania do soneto ou o surgimento de novas formas poéticas. Por conseguinte, os poetas não deveriam perder tempo buscando o novo, o que ainda não foi feito, mas descobrir em cada circunstância o que precisa ser feito, transformar o make it new de Ezra Pound em make it necessary. A crise da poesia, segundo Domeneck, se deve ao desconhecimento do contexto contemporâneo, ao qual reagiram com mais presteza e entusiasmo outras artes, como a música, a moda e as artes plásticas, não por acaso mais reconhecidas pelo público. Daí a formulação final, "form is nothing more than the intention of context", inspirada numa frase de Robert Creeley. ${ }^{\text {? }}$

\footnotetext{
${ }^{4}$ Cf. COMPAGNON. Os cinco paradoxos da modernidade, p. 117.

${ }^{5}$ DOMENECK. a cadela sem Logos, p. 119, 128.

${ }^{6}$ DOMENECK. Ideologia da percepção ou algumas considerações sobre a poesia contemporânea no Brasil, p. 182.

${ }^{7}$ DOMENECK. Ideologia da percepção ou algumas considerações sobre a poesia contemporânea no Brasil, p. 210.
} 
Essa valorização do contexto/ambiente, que se oferece como proposta à nova geração de poetas, não deve ser confundida com o surrado determinismo, como adverte o autor, ou com a "guetificação" promovida recentemente pelos "estudos culturais" (a subordinação da literatura a aspectos extraliterários como raça, estrato social, sexo, orientação sexual do autor ou, numa palavra, a diluição da literatura no caldo grosso da cultura). Podemos acrescentar que ela também não guarda nenhuma relação com a crítica materialista/ dialética que se desenvolveu no Brasil sob a influência de Antonio Candido e dos intelectuais da revista Clima, cujas obras revelam a preocupação com o drama da identidade brasileira ou a "penosa construção de nós mesmos", conforme a expressão de Paulo Emílio Sales Gomes. Suplantando os limites de outras abordagens sociológicas e especialmente a velha concepção da arte como espelho da sociedade, o autor do clássico Formação da literatura brasileira buscou sempre o "externo que vira interno", o social que habita dentro do literário, e desse modo conseguiu a façanha de resistir ao postulado formalista do texto como unidade fechada em si mesma, fora do tempo e do espaço, sem renunciar à idéia da autonomia do estético. ${ }^{8}$ Mas essa "idéia social de forma" e o empenho formativo/evolutivo nada significam aos olhos de Domeneck. Reagindo contra "noções viciadas de brasilidade", herdadas dos românticos e dos modernistas, ele mostra mais simpatia pela visão do ensaísta português Abel Barros Baptista (um crítico do confinamento da arte a seu contexto nacional), e por isso também ataca o "protecionismo de alfândega" que estaria por trás da idéia de um sistema literário brasileiro. ${ }^{9}$

Se a tradição cultural do país e as matérias tropicais não têm serventia para o poeta que cruzou o oceano, qual é, então, o contexto que importa? O da arte internacional, cada vez mais imbricada com o corpo, a performance, o espetáculo e o colapso das dicotomias? O da cultura pós-moderna, cujos principais traços, segundo Frederic Jameson, são o pastiche e a esquizofrenia? ${ }^{10} \mathrm{O}$ que se busca é a liberdade de flutuar entre diversos contextos, seguindo a lógica da própria globalização? Embora defenda o poder das coordenadas biográficas e culturais na configuração da linguagem de um Paul Celan, por exemplo, Domeneck, como bom anfíbio, assume uma visão dupla, que poderíamos chamar de contraditória, hesitando muitas vezes entre a força do condicionamento e o desejo de anulação das diferenças, de expansão e indeterminação. Noutras palavras, parece dividido entre a idéia romântica da historicidade da arte e o mito pós-moderno da transistoricidade, do eterno movimento, da multiplicação incessante de contextos tal como a sentem os artistas contemporâneos, "perdidos no espaço", infensos a quaisquer limitações.

\footnotetext{
${ }^{8}$ Cf. MERQUIOR. O texto como resultado, p. 121-131. Na conclusão de seu estudo sobre o "duelo" entre Antonio Candido e os "poetas-críticos" da revista Noigandres, Leda Tenório da Motta afirma que "a guerra dos textuais e dos contextuais" é uma peleja antiga no Brasil, que vem desde o século XIX, com a oposição entre os críticos Sílvio Romero e José Veríssimo (cf. MOTTA. Sobre a crítica literária brasileira no último meio século, p. 202).

${ }^{9}$ DOMENECK. Ideologia da percepção ou algumas considerações sobre a poesia contemporânea no Brasil, p. 198.

${ }^{10}$ Cf. JAMESON. Pós-modernidade e sociedade de consumo, p. 16-26.
} 
saber-se não em

todos os lugares

e às vezes

em lugar nenhum

mas alhures $[\ldots]$

Nesse "território flutuante" (o termo é de Michel Maffesoli), nenhuma estabilidade é possível, tudo se relativiza e a própria realidade se converte em ilusão, apreendida de modo reticente pelas palavras. Esse é o clima reinante em parcela significativa da poesia brasileira contemporânea - uma "poética da des-esperança", na expressão de Eduardo Sterzi, em que está suspensa a preocupação com a memória pessoal e familiar, tão abundante nas "mitologias privadas" do modernismo. ${ }^{11}$ Segundo Jameson, a cultura pósmoderna não abriga mais a concepção de um "eu singular", decisiva na conformação da estética da modernidade. Assassinado pelos pós-estruturalistas, o sujeito individual passou a ser visto como coisa do passado, pois a ninguém mais é dado possuir um "mundo privado e único". ${ }^{12}$ De toda maneira, ainda que transformado, o mito resiste. Domeneck leva às últimas conseqüências a fixação por essa miragem e realiza, a exemplo de Murilo Mendes, uma "mitização da vida cotidiana". Em sua obra, mais do que os contextos coletivos, o que importa é a soma de escolhas e acasos que delimitam o seu espaço/tempo individual. Ao final de a cadela sem Logos, a biografia do autor é apresentada com profusão de detalhes - sem "economizar no ego", para usar a expressão que aparece num dos poemas. Nas três partes do livro, o leitor sente o acúmulo dos objetos familiares ao poeta, das confusões de sua vida privada, de suas leituras, amizades, afeições intelectuais, idéias fixas. Por todos os textos, há essa exposição minuciosa da personalidade - bem típica, aliás, da cultura narcisista e hedonista da pós-modernidade, com seu apego às tribos e aos "umbigos". ${ }^{13}$ Ganha valor tudo que parece ínfimo, desde que seja íntimo e particular. O poeta sai em busca da "condição do único", do contexto específico que pôde "gerar o irrepetível".

$$
\begin{aligned}
& \text { minhas unhas } \\
& \text { querem meu } \\
& \text { próprio sangue } \\
& \text { o particular existe } \\
& \text { entre camadas de } \\
& \text { pele o singular } \\
& \text { necessita } \\
& \text { da comparação dos } \\
& \text { numerosos }
\end{aligned}
$$

Não é só a condição de viajante invisível - sujeito periférico sonhando com o centro do vasto mundo - que impõe a onipresença do "eu centralizador". Esse desejo tem a ver, sobretudo, com a necessidade de afirmação do indivíduo que se percebe

\footnotetext{
${ }^{11}$ Cf. STERZI. O mito dissoluto, p. 60-77.

${ }^{12}$ JAMESON. Pós-modernidade e sociedade de consumo, p. 19.

${ }^{13}$ Num artigo publicado recentemente, Robert J. Samuelson comenta o gosto dos internautas pela exposição de sua própria privacidade, transformando o exibicionismo em grande negócio: "Podem chamála de exibicionet. Acontece que a internet desencadeou o maior surto de exibicionismo em massa da história humana. [...] Tudo nesses sites é um clamor por atenção: olhem para mim, escutem-me, riam comigo - ou de mim" (SAMUELSON. Uma web de exibicionistas).
} 
diferente - "eu não compartilho das preferências da maior parte dos homens", afirma o poeta. Segundo ele, as mulheres, os negros e os homossexuais sentem com mais facilidade os "condicionamentos ideológicos das formas" do que os poetas masculinos, brancos e heterossexuais - os mesmos responsáveis, segundo ele, pelo logocentrismo que tomou conta da poesia brasileira. Mas o apego ao contexto não traz os riscos do confinamento e da incomunicação? Ao analisar a obra de Valdo Motta, poeta de origem pobre, negro, homossexual, sem emprego e sem moradia, Iumna Maria Simon observa que ele não derrapa na piedade de si mesmo e nem na automistificação. Em vez de se deter na simples exposição biográfica, procura generalizar a circunstância existencial: "sofrendo o vexame das várias segregações, Valdo Motta quis ir além das vivências imediatas". ${ }^{14}$ Domeneck, no entanto, propõe justamente o contrário: instaurar o movimento centrípeto de uma "singularização de generalidades", localizando na relação da biografia individual com a coletividade histórica o "único meio real de expressão do poeta". ${ }^{15}$

A confiança mútua das secreções: a saliva do narrador de histórias com a mesma transparência da saliva do ouvinte. Se está chovendo enquanto caminho por uma rua da antiga Berlim Oriental e penso este início, quanto o caminho, a velocidade dos passos e o vento frio no rosto influenciam o ritmo desta oração?

Assim começa o ensaio ou poema em prosa "Composição como contexto", terceira parte do livro a cadela sem Logos, no qual o autor reafirma que "o desgaste das formas dá-se menos pela hipertrofia do uso do que pela atrofia do contexto". Caberia perguntar a quem interessam as contingências que cercam a produção de um poema. Está claro que a circunstância é poetizável, como escreveu Drummond, mas deixa de ser circunstância quando se incorpora à poesia: "Arte de transfigurar as circunstâncias, poderíamos rotular a poesia". ${ }^{16}$ Parece correto supor que a poesia perdeu fôlego por causa de seu distanciamento em relação ao contexto histórico, mas os acidentes da produção individual de uma obra nada têm a ver com esse problema, que dificilmente será resolvido com a mera hipertrofia do contexto pessoal. O recuo ao "mundinho" pode ser reconfortante para quem vive a experiência do nomadismo, mas é preciso lembrar que os leitores estão sempre "alhures", que o excesso de referências pessoais não expande, limita, e que a arte não se constrói, afinal, sem o mínimo de "desap-ego".

A defesa romântica da subjetividade e a reação contra o intelectualismo são características da poesia de Ricardo Domeneck que nos remetem à "egolatria" em voga nos anos 1970, tempos da contracultura e da poesia marginal. Nos dois casos, trata-se de uma luta contra o formalismo, a objetividade e a despersonalização das poéticas construtivas, que dominaram o país na segunda metade do século XX. Dialogando com

\footnotetext{
${ }^{14}$ SIMON. Revelação e desencanto: a poesia de Valdo Motta, p. 209-233. Segundo Theodor W. Adorno, o paradoxo da lírica reside justamente na sua capacidade de extrair o universal da mais restrita individuação: "O conteúdo de um poema não é a mera expressão de emoções e experiências individuais. Pelo contrário, estas só se tornam artísticas quando, exatamente em virtude da especificação de seu tomar-forma estético, adquirem participação no universal" (cf. ADORNO. Lírica e sociedade, p. 193). ${ }^{15}$ DOMENECK. Ideologia da percepção ou algumas considerações sobre a poesia contemporânea no Brasil, p. 209.
}

${ }^{16}$ ANDRADE. Manuel Bandeira, p. 1434. 
João Cabral já no título a cadela sem Logos, Domeneck faz paródia à moda antiga, isto é, com humor, embora tenha escolhido citar um dos livros menos metalingüísticos do poeta pernambucano, verdadeiro mergulho no seu contexto regional, o Capibaribe descrito no Cão sem plumas. No lugar da contenção e da objetividade, Domeneck propõe o transbordamento da expressão em poemas longos e discursivos que, segundo ele, crescem "por metástase". Ao produto acabado, prefere a noção de processo, que vem crescendo em outras artes, mas que também poderíamos associar à linguagem inacabada - "escrita da procura", segundo Antonio Candido - praticada por Clarice Lispector. Em vez do cálculo e da linha reta, defende o acaso, o tortuoso, a "vertigem do arbitrário".

\author{
[...] pés descalços \\ levantam mais poeira \\ que uma blasfêmia \\ sobre \\ a mesa então \\ suponho que \\ o chão provenha \\ mais espaço \\ para o \\ tortuoso o \\ artifício \\ sobrevive com \\ naturalidade \\ esta sou eu a \\ cadela sem \\ Logos
}

Essa crítica ao logocentrismo, porém, não tem como únicos destinatários João Cabral e a poesia concreta, com sua ênfase na pureza dos significantes. Ela se inscreve no contexto bem mais amplo da "epistemologia anarquista ou não racional" instaurada pela cultura pós-moderna. O projeto da modernidade, formulado desde o século XVIII com fundamento na razão, no Estado de Direito e na liberdade, entrou em crise. No seu lugar, houve a suspensão das dicotomias (novo/antigo, esquerda/direita, cultura erudita/cultura de massa etc.) e a substituição da dialética - alma da modernidade - por valores como ecletismo e indeterminação. ${ }^{17}$ Sendo típico da sociedade pós-industrial, o irracionalismo comporta, sem dúvida, aspectos de reacionarismo, além de revelar, especialmente no caso de Domeneck, uma forte inclinação para o mito (que tem o condão, como se sabe, de conciliar todas as contradições). O desejo de retornar à água (ou indiferenciação) das origens salta à vista desde o primeiro livro desse poeta leitor da Bíblia, chegado a experiências místicas. O próprio título, Carta aos anfíbios, tem como explicação essa procura do mítico:

O duplo percorre todo o livro, mas na imagem do anfíbio, habitante do duplo em unidade. Esse "anfíbio" é informado pela leitura de Mircea Eliade e sua defesa de que mesmo no mundo moderno aparentemente mais dessacralizado o ritual, o mítico e o sagrado sobrevivem, ainda que nas formas mais confusas. ${ }^{18}$

\footnotetext{
${ }^{17}$ Cf. COMPAGNON. Os cinco paradoxos da modernidade, p. 112 e 124.

${ }^{18}$ DOMENECK. Entrevista, p. 120.
} 
É estranho que, a despeito de possuir essa "simpatia pelo todo", o poeta considere a metáfora algo fora de moda e tenha resolvido excluí-la dos seus procedimentos poéticos - acompanhando, nesse passo, a pedagogia de João Cabral. Nos seus textos, há um nítido empenho de substituição da metáfora pela metonímia ou, em muitos casos, pela simples exposição de argumentos - uma prosa diagramada em versos, cheia de substantivos abstratos, na qual o poeta usa e abusa da descontinuidade e dos anacolutos, abrigando, nessa forma assumidamente inacabada e informe, o seu caudal de referências pessoais. O resultado, claro, aparece fortemente marcado por confusão, obscuridade e ausência de foco (como uma língua estrangeira). São efeitos que Domeneck também confessa buscar, embora critique em vários momentos o hermetismo dos poetas contemporâneos, que deram as costas para o mundo e em troca de sua saliva vêm obtendo apenas "ouvidos moucos à poesia". E seus textos quase criptografados teriam o poder de aumentar esse público? Ou o aggiornamento da poesia, que o poeta defende como necessário no contexto contemporâneo, implicaria na verdade a negociação do seu desaparecimento? Essa seria uma maneira de compreender não apenas a ênfase no procedimento da metástase, e a conseqüente aniquilação da forma poética, mas o próprio fechamento dessa poesia em seu âmbito privado - como se o poema fosse uma carta destinada aos amigos próximos, ou a si mesmo. Mas Domeneck tem paixão sincera pela poesia, além do desejo quase profético de intervenção. Resta esperar pelo grande salto que certamente virá - quando esse anfíbio deixar de tropeçar em suas próprias irresoluções.

\section{A B S T R A C T}

Ricardo Domeneck, a young Brazilian poet who lives in Berlin, has published two books and some essays about contemporary poetry that stimulate us to think about important questions related to post-modernism, like nomadic existence, fluctuation among territories and search of identity. Although he lives in "no place", the poet believes in the influence of context and cultural conditions upon the artistic creation. This attachment to context means in reality a fascination with chance (against modern "logocentrism") and a great appreciation of subjectivity (in spite of post-modern displacement).

\section{KEYWORDS}

Ricardo Domeneck. Brazilian contemporary poetry.

Post-modern culture.

\section{REFERÊNCIAS}

ADORNO, Theodor W. Lírica e sociedade. In: BENJAMIN, Walter et al. Textos escolhidos. São Paulo: Abril Cultural, 1980.

ANDERSON, Perry. Modernidade e revolução. Trad. Maria Lúcia Montes. Novos Estudos Cebrap, São Paulo, n. 14, fev. 1986.

ANDERSON, Perry. As origens da pós-modernidade. Trad. Marcus Penchel. Rio de Janeiro: Jorge Zahar, 1999. 
ANDRADE, Carlos Drummond de. Manuel Bandeira. In: . Poesia e prosa. Rio de Janeiro: Nova Aguilar, 1992.

AZEVEDO, Carlito. Uma vez humano sempre acrobata. Jornal do Brasil, Rio de Janeiro, 30 jul. 2005. Caderno Idéias.

COMPAGNON, Antoine. Os cinco paradoxos da modernidade. Trad. Cleonice P. B. Mourão, Consuelo F. Santiago, Eunice D. Galéry. Belo Horizonte: Editora UFMG, 2003.

DOMENECK, Ricardo. Entrevista. Inimigo Rumor, Rio de Janeiro, n. 17, 2. sem. 2004/ 1. sem. 2005.

DOMENECK, Ricardo. Ideologia da percepção ou algumas considerações sobre a poesia contemporânea no Brasil. Inimigo Rumor, Rio de Janeiro, n. 18, 2. sem. 2005/ 1. sem. 2006.

FERNANDES, Pádua. Duas estréias, três poetas e o outro inumerável: Angélica Freitas, Marília Garcia e Ricardo Domeneck. K, Jornal de Crítica, São Paulo, n. 10, abr. 2007.

FERNANDES, Pádua. Correio em seco: Ricardo Domeneck e a poesia de Carta aos anfíbios. Germina: Revista de Literatura e Arte, São Paulo, mar. 2006.

HABERMAS, Jürgen. Modernidade - um projeto inacabado. In: ARANTES, Paulo Eduardo; ARANTES, Otília Beatriz Fiori (Org.). Um ponto cego no projeto moderno de Jürgen Habermas. São Paulo: Brasiliense, 1992.

JAMESON, Frederic. Pós-modernidade e sociedade de consumo. Trad. Vinícius Dantas. Novos Estudos Cebrap, São Paulo, n. 12, jun. 1985.

MERQUIOR, José Guilherme. O texto como resultado. In: ARINOS, Affonso et al. Esboço de figura: homenagem a Antonio Candido. São Paulo: Duas Cidades, 1979.

MORICONI, Italo. Em cena: poesia novíssima. Jornal do Brasil, Rio de Janeiro, 23 jul. 2005. Caderno Idéias.

MOTTA, Leda Tenório da. Sobre a crítica literária brasileira no último meio século. São Paulo: Imago, 2002.

NAGIB, Lúcia. A utopia no cinema brasileiro. São Paulo: Cosac Naify, 2006.

PAIXÃO, Fernando. Uma poesia em trânsito. Cult: Revista Brasileira de Cultura, São Paulo, n. 112, abr. 2007.

SAMUELSON, Robert J. Uma web de exibicionistas. O Estado de S. Paulo, São Paulo, 23 set. 2006.

SIMON, Iumna Maria. Considerações sobre a poesia brasileira em fim de século. Novos Estudos Cebrap, São Paulo, n. 55, nov. 1999.

SIMON, Iumna Maria. Revelação e desencanto: a poesia de Valdo Motta. Novos Estudos Cebrap, São Paulo, n. 70, nov. 2004.

STERZI, Eduardo. O mito dissoluto. Jandira: Revista de Literatura, Juiz de Fora, Funalfa Edições, n. 1, 2004.

TERRON, Joca Reiners. Perdidos no espaço. Folha de S. Paulo, São Paulo, 24 fev. 2007. Caderno Ilustrada. 